Article

\title{
From Environmental to Sustainability Programs: A Review of Sustainability Initiatives in the Italian Wine Sector
}

\section{Chiara Corbo *, Lucrezia Lamastra and Ettore Capri}

Istituto di Chimica Agraria ed Ambientale, Università Cattolica del Sacro Cuore di Piacenza, 29122 Piacenza, Italy; E-Mails: lucrezia.lamastra@unicatt.it (L.L.); ettore.capri@unicatt.it (E.C.)

* Author to whom correspondence should be addressed; E-Mail: chiara.corbo@unicatt.it; Tel.: +39-05-2359-9220; Fax: +39-05-2359-9217.

Received: 15 January 2014; in revised form: 27 February 2014 / Accepted: 2 April 2014 / Published: 15 April 2014

\begin{abstract}
The Italian wine industry is strongly committed to sustainability: the stakeholders' interest for the topic is constantly growing and a wide number of sustainability programs have been launched in recent years, by both private businesses and consortiums. The launch of these initiatives has signaled the commitment of farmers and wine producers to the implementation of sustainability principles in viticulture and wine production, which is a positive signal. Unfortunately, however, the varied design of the sustainability initiatives and the differences in the objectives, methodologies, and proposed tools risks to create confusion, and undermine the positive aspects of these initiatives. In order to bring some clarity to this topic, we herein present a comparison of the most important sustainability programs in the Italian wine sector, with the overall objective of highlighting the opportunity to create synergies between the initiatives and define a common sustainability strategy for the Italian wine sector.
\end{abstract}

Keywords: wine; sustainability; Italy; sustainability programs

\section{Introduction}

Although the wine industry can be seen as less "dirty" than other sectors, as for example the chemical one $[1,2]$, wine producers and vine growers have been increasingly engaged in sustainability driven by different forces, first of all the environmental concerns. The wine industry, indeed, has to face a number of environmental issues and challenges. The literature reports several environmental 
sustainable practices and these aspects are often mentioned as relevant: soil management, water management, wastewater, biodiversity, solid waste energy use, air quality, and agrochemical use [3]. Producers have to limit the use of chemicals, promoting their sustainable use in order to preserve and enhance the level of biodiversity and soil fertility. Water must also be managed responsibly by minimising consumption and reducing run-off of contaminated wastewater. Furthermore, wineries must manage the landscape, to protect the health and safety of workers, as well as minimize its impact on the community (from chemical spray drifts, odor, and noises) [1,2].

The global wine industry also faces institutional and stakeholders pressures. The pressures from governments and environmental groups, the growing interest from consumers for green products and the higher commitment to export in countries with a strong attention for "sustainable products" are among the "institutional drivers" to sustainability [4-6]. Finally, managers' personal values, entrepreneurs' personal motivations, and employees' environmental attitudes can be considered as important drivers to guide the wine industry towards sustainability, given the fact that the sector is mainly made by small-medium companies, and there is a frequent coincidence between the ownership and the management [6]. Moreover, in the wine sector, preserving the environment is a sort of "natural instinct" for winemakers, concerned in maintaining proper environmental conditions and in preserving the natural resources in order to maintain the productivity of the land, not only for the present business but also to the future generations of winemakers that will manage the farm [7].

The term "sustainability" also has to be interpreted from a social and economic point of view: only an equal consideration of the ecological, economic and social dimensions of sustainability can lead to the achievement of (among the others) "changing unsustainable patterns of production and consumption and protecting and managing the natural resource base of economic and social development" [8]. Therefore, the three interdependent and mutually reinforcing pillars of sustainability must always be jointly considered in order to define viticulture as "sustainable", promoting aspects such as, the health and safety of workers, the Company's contribution to the rural and local development, and the economic viability and profitability of the measures taken.

The importance of considering all the dimensions is clearly laid out in the definition of "sustainable viticulture" given by the "Organisation Internationale de la Vigne et du Vin" in its Resolution of the Comité Scientifique et Technique (CST) 1/2004 addressing the issue of sustainability in the production of grapes, wines, spirits, and other vine products [9], and laying the foundations for the guidelines for the production, processing and packaging of products further released in 2008 [10]. Sustainable viticulture, hence, has been defined as a "global strategy on the scale of the grape production and processing systems, incorporating at the same time the economic sustainability of structures and territories, producing quality products, considering requirements of precision in sustainable viticulture, risks to the environment, product safety and consumer health, and valuing of heritage, historical, cultural, ecological, and aesthetic aspects".

At the International level, Countries in the "New Wine World" have been the pioneers in introducing sustainability in the wine industry (vine growing and wine production): In 1992, the Lodi Winegrape Commission from California launched an Integrated Pest Management program that is considered the "foundation" of sustainability winegrowing programs. Since then, several guidelines and programs for sustainable winegrowing and production have been defined by institutions and organizations around the world: for example, the "California Sustainable Winegrowing Alliance" in 
California, the "Wine Sustainable Policy" in New Zealand and the "Integrated Production of Wine Scheme" in South Africa [5,11]. However, it is important to highlight that although the development of several sustainability initiatives and the establishment of a number of certification schemes-a univocal definition of "sustainable viticulture" still does not exist, and nor do internationally recognized sustainability indicators. Furthermore, the integration of social and economic aspects of sustainability still seems quite insufficient [12].

Italy has now also stepped up to the challenge. Although the widest number of publications and projects regarding sustainable wine have been produced in countries other than Italy [13] the quantity of academic literature dedicated to the topic of sustainability in the Italian wine sector is increasing [14], with particular focus on environmental sustainability indicators [15-17] greenhouse gas emissions and the use of Life Cycle Assessment methodology [18-20]. Sustainability has often also been a dominant element for international wine conferences and events recently held in Italy. For example, the issue of sustainability in the wine sector was included among the topics of the international event "Vinitaly 2013" (the major Italian fair in the wine sector) and 2014's edition will host a special area dedicated to organic wine. In May 2013, at the International Congress "Enoforum 2013", several sessions were dedicated to sustainability, and in November 2013, the International Congress "Sustainable Viticulture and Wine Production: steps ahead toward a global and local cross-fertilization" was hosted in the framework of the XXV International Enological and Bottling Equipment Exhibition ("Salone Internazionale Macchine per Enologia e Imbottigliamento"-SIMEI). Apart from the interest from the research world, the most consistent sign of interest for sustainability in the wine sector in Italy can be considered the wide range of sustainability programs launched in recent years by private producers and consortiums. It looks like a "wave" of sustainability is overwhelming the entire sector and if, on one hand, this is a positive signal of the concern regarding the issue of sustainability in viticulture, on the other hand confusion can arise among vine growers and wine producers. The large number of different strategies, guidelines and practices, indeed, make their comparison extremely complicated, and there is the risk that farmers and producers do not have a clear understanding of the opportunities and benefits deriving from the implementation of a certain sustainability program. The lack of clarity can also affect consumers, due to the growing range of wines sporting "sustainability-sounding" names and adjectives (such as sustainable, organic, natural, free, eco-friendly, etc.), but adequate explanations do not always accompany these names.

In this paper, the authors report on a comparative and qualitative analysis of several sustainability programs currently being used in the Italian wine industry. Due to the lack of similar studies in the Italian context, the authors tried to use a new approach, as pragmatic as possible, basing the evaluation of the sustainability programs on parameters, such as the presence of certain elements in the program (sustainability protocol, practical tools for the sustainability improvement, certifications, and labels), the scientific consistency and originality, marketing and communication issues. The information for this research was obtained through interviews with the managers and supervisors of the selected programs. The overall objective was to underline the similarities and differences between programs, and suggest a new approach built on the cooperation and integration between the numerous initiatives in order to create a unique framework for sustainable vitiviniculture in Italy.

This paper begins with the presentation of the objective, and the research method is also outlined, followed by the presentation of results. Further discussions are presented in the final section. 


\section{Objective}

This study reviews the most relevant sustainability programs in the Italian wine industry, in order to underline the main features of each program and highlight how they differ from each other in terms of objectives, assessment methodologies and tools, innovative and scientific features, as well as level of completeness and transparency. Rather than stating the validity or the efficacy of the considered sustainability programs, this work aims to undertake an evaluation that can generate the information needed to build a tailored sustainability framework for the Italian wine sector, an approach that could bring uniformity to the sector, while still taking into consideration the specific needs of each company.

\section{Methodology}

In the first phase, a literature review was conducted in order to know if similar analyses (about the comparison of sustainability initiatives in the wine sector) had been previously produced. The existence of some papers about the cross-cultural comparison of sustainability practices in the wine sector [5] or the use of Environmental Management Systems in a specific area (namely New Zealand) [21] have been found, but unfortunately not so many examples of papers specifically referring to this topic (particularly regarding Italy) have been detected at the moment the authors were writing this article. Hence, due to the lack of similar analysis, the authors developed a pragmatic approach that was followed for the review and analysis of the selected programs.

\subsection{Programs Selection}

The sustainability programs analyzed were chosen based on an analysis of the "state of the art" of sustainability initiatives in the wine sector, meaning the most "relevant" initiatives at the moment existing in Italy according to the number of wineries joining the programs, the participation in congresses, and the number of informative articles in sector magazines and journals.

It is important to underline that nowadays a wide variety of sustainability initiatives have been implemented by single wine makers, but the focus of this paper is on membership programs. This choice has been driven first of all by the final objective of this work, which is to highlight the necessity of creating a unique sustainability framework that could fit the widest possible number of Italian wineries. Secondly, the importance of Institutions and Industry Associations in influencing the "sustainable awareness" has been highlighted by several researchers: it is enough to think of California's experience, where the creation of strong local organizations have brought about the successful "collaborative sustainability" [14,22]. Corporate Activism can also be seen as an important driver for sustainability in the wine sector. Collaborative working can be a tool to enhance the spread of knowledge, as well as to reduce the risks and minimize the costs deriving from the implementation of sustainability initiatives. Being part of a "sustainability network" is, for the single winery, an opportunity to enhance and reinforce their relationship with Institutions, sponsors, consumers' associations and society. Finally, for a large part of consumers to know that the winery is part of a sustainability network that is managed by a credible group, a Trade Association or an Institution can be interpreted as a guarantee of truthfulness.

The following sustainability initiatives have been selected for the analysis: 
- Tergeo

- Magis

- SOStain

- V.I.V.A. ("Valutazione dell'Impatto della Vitivinicoltura sull'Ambiente") Sustainable Wine

- ECO-Prowine

- Ita.Ca/Gea.Vite

- Vino Libero

- New Green Revolution (Montefalco 2015)

- Organic wine

- VinNatur

The choice of including organic wine was made because-although not clearly claimed as "sustainable" - organic production can be interpreted by consumers as "environmental friendliness". Minimization of inputs in the vineyard and the cellar organic practices confers the idea of an environmentally friendly wine, both from the consumer's and the producer's point of view [23-26].

The association between the characteristics of sustainability and organic has often been made by researchers analyzing environmental protection initiatives or management systems in the wine sector (e.g., [1,27,28]) In the review of studies about the perception of organic food presented by Schleenbecker and Hamm it was noticed that, beside aspects as nutrition and animal welfare, the belief that these products are less damaging for the environment can drive the choice of organic food [29]. Organic food associations themselves claim that their products are more respectful of the environment (for example, the official website of the Italian Association for Organic Farming reports that organic farming is able to offer solutions for a more "environmentally friendly" agriculture [30]) For this reason, we decided to include organic wine in our analysis.

For similar reasons (confusions between the words "sustainable" and "natural") we also decided to include in the analysis an association of "natural wine" producers (VinNatur), as a representative of the Natural Wine movement and philosophy.

\subsection{Data Collection}

Data and information, collected between May and November 2013, were firstly taken from the website and informative material (brochures, advertisements, press releases, etc.) available for each program. At a later stage, a representative of each program was contacted (informally, or via email/professional networks) and interviews were held over the phone and/or via email exchanges in order to gain additional information and verify that previously collected. Interviewees were also asked to confirm the correctness of the information collected from websites, informative materials, and congresses and conferences. The interview started by presenting the scope of the research, then questions were asked in order to obtain the following information:

- General purposes and objective of the program/initiative;

- Implementation status of the program;

- Presence or absence of specific elements (listed in Section 3.3.1 "Glossary");

- Which elements of the so-called "three pillars" of sustainability are accounted for in the program; 
- "Boundaries" of the program: is sustainability only considered in the vineyard, or are the cellar practices also analyzed?

- Names of the subjects designing and promoting the program;

- Presence of elements related to transparency and communication, such as emission of a sustainability report for participants of the program, availability (to consumers) of the evaluating system used, the presence of a website, and a sustainability labeling scheme;

- Presence of a third party verifier for certification or validation of the winery's results.

The same questions were posed during each interview. After this phase of interviews, a specific "card" was filled in for each program, listing all the information collected and it was sent to the interviewee in order to verify its correctness [31]. The last step was to create a comprehensive document listing all the information collected for each program in order to facilitate the comparison of all the information.

\subsection{Analysis}

In order to conduct the analysis, two preliminary steps were defined, namely: (1) The creation of a "Glossary" and (2) The definition of the analysis methodology.

\subsubsection{Glossary}

The word "sustainability" has so many definitions that some authors speak about a wide variety of "green nuances" [14]: there is no single sustainable behavior, nor is there a single definition of elements included in the various sustainability programs. Hence, the first step was to establish a common terminological base, a "glossary" according to which the analysis could be conducted.

The following words were defined:

- Sustainability Protocol in this context, defines the "document" that states the requirements a producer has to satisfy and/or the management and behavioral standards to be followed in order to reach sustainability goals and to be admitted to join the program. It should not be confused with technical disciplinary or assessment manuals (since their scope is to provide practical guidelines and tools to improve sustainability) [32].

- Management tools are defined as practical tools provided by the program for sustainability assessment and improvement. Examples of management tools are the self-assessment questionnaires (also called "checklist"), the technical/scientific tools (e.g., a web-platform for sustainability assessment), the guidelines (more detailed if compared with the Protocol), the training tools (workshops, seminars, manuals, etc.) and the specific indicators to be used for the evaluations (for example: a program requiring companies to assess social sustainability by means of the calculation of indicators as the number of women employed in the company or the employees' turn-over).

- Calculators are used to express a concise and comparative measure of sustainability performances. Hence, they are used to explicate complex results in a single measure (e.g., Carbon Footprint, Water Footprint, or a final indicator of sustainability). 
- Validation is the procedure through which the compliance with the program's rules, the transparency and accuracy of information, the achievement of a minimum level of sustainability are checked. These checks can be conducted by the program's staff, or by a third party.

- Certification is the outcome of a formal process by which an independent and accredited Body declares that a product or a system is in compliance with a specific standard (rules or regulation) provided by an International Body (e.g., ISO standards).

\subsubsection{Definition of the Analysis Methodology}

The "analysis" consists in the examination of the gathered information and the coherence between what was stated by the interviewed persons and the information collected in the previous phase. When something was not clear enough, explicit explanations were sought from the program's responsible person(s). The analysis was then developed according to the following steps:

- Definition of the implementation status of each program (definition phase, pilot phase, operating).

- Detection of the elements. The presence of the series of elements defined in the program (Protocol, Management Tools, Calculators, Label, Validation, Certification) was detected.

- Analysis of completeness. For each program analyzed it was asked and reported which "sustainability pillars" were taken into account (if only the Environmental or also the Economic and Social aspects were considered) and-within each area-which elements were taken into account, namely [33]:

a. Environmental pillar: Air, Water, Soil, Biodiversity, Energy management, Packaging, Transports, Pesticides and Fertilizers, Waste Management, Landscape, Raw Materials (this last one-"Raw Materials"- means that the program evaluates the attention from producers dedicated to the sustainability of the materials they purchase for their operations).

b. Economic: Direct Economic Impacts, Indirect Economic Impacts, Evaluation of the territorial resources raw material and labor force), responsibility towards workers (health, safety, training, etc.).

c. Social: Responsibility towards residents and inhabitants (people living nearby the farm), responsibility toward the local community, responsibility toward consumers.

- Analysis of the boundaries (if the sustainability program covers operations in the Vineyard, in the Cellar, or both).

- Analysis of the consistency in terms of science and innovation (Academic bodies and Institutions involved in the project; innovation level).

- Analysis of the transparency and communication aspects (availability and clarity of information available to the consumers and stakeholders, in the form of sustainability reports, labeling, websites, availability of the evaluation system used by the program to assess the sustainability of the winery).

- Analysis of the "sustainability label", its content and the provided information.

- Analysis of the "verification" type. A distinction between in/out values and "gradual" vales has been made. Indeed, observing the majority of the sustainability programs, it was seen that in order to be accepted in a certain program, or to have access to a label or certification, some 
programs ask their wineries to comply with certain rules, whereas other times it is a matter of respecting values or thresholds. Therefore, the analysis was conducted according to this distinction.

- Analysis of an independent third party involvement (for validation or certification, if provided).

\section{Program Description}

Table 1 summarizes the main features of the selected programs.

Table 1. Name and descriptions of the Italian sustainability initiatives analyzed in the study.

\begin{tabular}{|c|c|}
\hline Name & Description \\
\hline Tergeo [34] & $\begin{array}{l}\text { An initiative of the UIV-Unione Italiana Vini, an Italian wine trade association. } \\
\text { Objective: to support the environmental, social and economic sustainability in the Italian wine } \\
\text { sector, enhancing the "knowledge and technology transfer" from Companies and Researchers to } \\
\text { farmers and wine producers. It acts like a "collector" of initiatives proposed by Companies, } \\
\text { Universities and Research Centers dedicated to the promotion of sustainability. Tergeo works } \\
\text { mainly with two instruments: the "Matrix" and the "Applications". The Matrix is an assessment } \\
\text { tool proposed by the Commitee to assess a company's "sustainability positioning". } \\
\text { "Applications" are tools proposed by the Partners (Research Centers, Universities, Company but } \\
\text { not wineries) that can help wine producers to be more sustainable. These tools are submitted for } \\
\text { evaluation by Tergeo Scientific Committee, that is composed by distinguished academic } \\
\text { Professors and Researchers and experts of the wine sector; they evaluate the proposal and, if it is } \\
\text { accepted, the "Application" is proposed to the members (producers and farmers) of the } \\
\text { Association. } \\
\text { Participation: } 170 \text { wineries and } 9 \text { main companies operating in the agricultural sector. }\end{array}$ \\
\hline Magis [35] & $\begin{array}{l}\text { A sustainability program initiated by Bayer CropScience in cooperation with the University of Milan. } \\
\text { Objective: to promote sustainability in viticulture and minimize environmental impact by using } \\
\text { precision viticulture techniques. Monitoring vineyards and distributing fertilizers or } \\
\text { agrochemicals in a more precise way to enable reduced interventions in the field, as well as } \\
\text { reducing the amount of wastes and the overall environmental impact. } \\
\text { Participation: approximately } 106 \text { wineries. }\end{array}$ \\
\hline SOStain [36] & $\begin{array}{l}\text { A sustainability program promoted by the Observatory for Productivity and Efficient use of } \\
\text { Resources in Agriculture - OPERA of the Università Cattolica del Sacro Cuore, in cooperation } \\
\text { with other Italian universities and research centers. } \\
\text { Objective: to promote environmental, social and economic sustainability in Sicily. The program is } \\
\text { characterized by the "cycle of continuos improvement", an iterative process through which each } \\
\text { winery can assess, monitor and improve its sustainability performances. } \\
\text { Participants: } 2 \text { big Sicilian wineries. The project is open to all the wineries in the region. }\end{array}$ \\
\hline V.I.V.A. Sustainable Wine [37] & $\begin{array}{l}\text { It is a project launched in } 2011 \text { by the Italian Ministry for the Environment, Land and Sea in order } \\
\text { to evaluate the wine-sector sustainability performance, based on Water \& Carbon Footprint } \\
\text { calculation, with the participation of some large Italian wine-producing companies, Universities } \\
\text { and Research institutes. } \\
\text { Objective: to establish a common methodology for the environmental, social and economic } \\
\text { sustainability assessment in the wine sector using } 4 \text { indicators (Air, Water, Vineyard, Territory) } \\
\text { and to propose a label and a smart-phone enabling the final consumers to recognize producers } \\
\text { committed to the Project. } \\
\text { Participation: } 9 \text { pilot companies. }\end{array}$ \\
\hline
\end{tabular}


Table 1. Cont.

\begin{tabular}{|c|c|}
\hline Name & Description \\
\hline ECO-Prowine [38] & $\begin{array}{l}\text { It is a European project funded under the framework CIP - EcoInnovation. } 6 \text { European countries } \\
\text { are participating (including Italy). } \\
\text { Objective: to promote sustainability in the wine sector through the use of LCA methodology and to } \\
\text { create a label for European sustainable viticulture. Social and economic aspects are also taken into } \\
\text { account, the latest through the use of Life Cycle Costing methodology. } \\
\text { Participation: } 105 \text { pilot wineries in Italy, Spain, Portugal, Bulgary, Greece, Austria. }\end{array}$ \\
\hline Ita.Ca/Gea.Vite $[39,40]$ & $\begin{array}{l}\text { Two sustainability initiatives promoted by an Italian Agronomic Institute (Studio Sata) } \\
\text { Objective: Ita.Ca (Italian Wine Carbon Calculator) is a tool to calculate the greenhouse gas } \\
\text { emissions, specifically set for the Italian wine sector, and built upon indications from the } \\
\text { International Wine Carbon Calculator (IWCC). Gea.Vite is a program to assess the efficiency and } \\
\text { sustainability of the winery. It is composed by several indicators and tools (Ita.Ca is one of the } \\
\text { tools in the program). } \\
\text { Participation: } 47 \text { wineries. }\end{array}$ \\
\hline Vino Libero [41] & $\begin{array}{l}\text { A program initiated by an Italian wine entrepreneur, who started with his products and then } \\
\text { involved other wineries. } \\
\text { The program aims mainly at promoting the production of wine free from chemical fertilizers, weed } \\
\text { killers and excess sulfites. } \\
\text { Participation: } 12 \text { producers, } 62 \text { restaurants, } 75 \text { winehouses. }\end{array}$ \\
\hline $\begin{array}{l}\text { New Green Revolution } \\
\text { (Montefalco 2015) [42] }\end{array}$ & $\begin{array}{l}\text { Started in 2009, the project has been developed by the Associazione Grandi Cru of the Italian wine } \\
\text { region "Montefalco Sagrantino". } \\
\text { Objective: creation of a environmental, social and economic sustainability protocol specifically } \\
\text { designed for the Region (a territorial model of sustainable development). } \\
\text { Participation: } 7 \text { wineries (all located in the Montefalco area). }\end{array}$ \\
\hline Organic wine [43] & $\begin{array}{l}\text { A wine can be defined "Organic" when it is produced according to the Regulation of the European } \\
\text { Commission (EC) no. 203/2012, that is: } \\
\text { (in the vineyard) produced from "organic" grapes; } \\
\text { (in the cellar) produced using only products and processes authorized by the Regulation (EC) No } \\
203 / 2012 \text {. } \\
\text { Until } 2012 \text {, there were no EU rules or definition of "organic wine". Only grapes could be certified } \\
\text { organic and only the mention "wine made from organic grapes" was allowed. In February } 2012 \text {, } \\
\text { new EU rules have been agreed. The new regulation has identified oenological techniques and } \\
\text { substances to be authorized for organic wine, including a maximum sulphite content (set at } 100 \mathrm{mg} \\
\text { per liter for red wine and } 150 \mathrm{mg} / \mathrm{L} \text { for white/rosé). }\end{array}$ \\
\hline VinNatur [44] & $\begin{array}{l}\text { VinNatur is a consortium of wineries (across all Europeo) producing so-called "natural wine". At } \\
\text { the present time, an official or legal definition for "natural wine" does not exist; however, there are } \\
\text { many unofficial codes of practices or definitions released by several associations of natural wine } \\
\text { producers. Objective: promoting a wine that is produced with the lowest possible number of human } \\
\text { interventions in the vineyard and in the cellar, in order to enhance the link } \\
\text { between the territory of origin, the final product and its taste. In general, "natural wines" are } \\
\text { produced from organically or bio-dynamically grown grapes. Grapes must be hand-picked, and no } \\
\text { sugars, foreign yeasts and bacteria must be used. The use of sulphites must be strictly limited, and } \\
\text { no heavy manipulation are permitted (micro-oxygenation, reverse osmosis, spinning cone, } \\
\text { cryoextraction. Participation: } 96 \text { producers in Italy (and } 66 \text { accross Europe). } \\
\text { pursued particularly limiting the quantity of sulfites and chemicals. } \\
\text { Participation: } 96 \text { producers in Italy (and } 66 \text { accross Europe). }\end{array}$ \\
\hline
\end{tabular}




\section{Results}

\subsection{Implementation Status}

The analysis was always conducted taking into account the current implementation status of the different programs, as showed in Table 2, according to the following definitions:

- Definition phase: project defined in all its components but still not tested on companies.

- Pilot phase: project already defined but in a testing phase on pilot companies.

- Operating: project fully working, already tested on companies and completely defined in all its components.

This type of information was requested in order to ensure the highest grade of objectivity of the analysis. Indeed, not all the projects are in the same phase of implementation and particularly for some elements - for example, the presence of a label to certify the adhesion of a winery to the program or the requirement for a sustainability report-we received answers during the interviews such as "this element is not present at the moment, but it is expected to be inserted later in the program". Hence, we decided to conduct the analysis on the base of the current status of each program, listed in Table 2.

Table 2. Implementation status of the analyzed sustainability programs.

\begin{tabular}{|c|c|c|c|}
\hline \multirow{2}{*}{ Programs } & \multicolumn{3}{|c|}{ Status } \\
\hline & Definition & Pilot & Operating \\
\hline Tergeo & & $\bullet$ & \\
\hline Magis & & & $\bullet$ \\
\hline SOStain & & & $\bullet$ \\
\hline V.I.V.A. & & $\bullet$ & \\
\hline ECO-Prowine & $\bullet$ & & \\
\hline Ita.Ca/Gea.Vite & & & $\bullet$ \\
\hline Vino Libero & & & $\bullet$ \\
\hline New Green Revolution & & & $\bullet$ \\
\hline Organic Wine & & & $\bullet$ \\
\hline VinNatur & & & $\bullet$ \\
\hline
\end{tabular}

Notes: The black spot indicates the "Status" (Definition, Pilot or Operating) of each program. Please note that this "Status" refers to the moment the authors are writing the article.

\subsection{Element Detection}

According to the "Glossary" defined at the beginning of the analysis, a "sustainability program" can be characterized by the presence of some main elements, namely a protocol, the management tools and a specific calculator (e.g., Carbon Footprint). Some programs have, as a final output, a label of sustainability, which is a useful way of informing consumers and stakeholders about the sustainability of a specific product and the commitment of the winery participating in the program. Finally, a program may also require the participating companies to undergo a verification (made by the program's staff or a third party) or a certification.

Results of the analysis are shown in the Table 3. 
Table 3. Results of evaluation of the elements of sustainability programs *.

\begin{tabular}{|c|c|c|c|c|c|c|}
\hline Programs & Protocol & $\begin{array}{c}\text { Management } \\
\text { Tools } \\
\end{array}$ & Calculators & Label & Verification & Certification \\
\hline Tergeo & & $\bullet$ & & & $\bullet$ & \\
\hline Magis & $\bullet$ & $\bullet$ & & $\bullet$ & $\bullet \bullet$ & \\
\hline SOStain & $\bullet$ & $\bullet$ & $\bullet$ & & $\bullet$ & \\
\hline V.I.V.A. & & $\bullet$ & $\bullet$ & $\bullet$ & $\bullet$ & \\
\hline ECO-Prowine & & $\bullet$ & $\bullet$ & $\bullet$ & $\bullet$ & \\
\hline Ita.Ca/Gea.Vite & $\bullet$ & $\bullet$ & $\bullet$ & & $\bullet$ & \\
\hline Vino Libero & $\bullet$ & $\bullet$ & & $\bullet$ & $\bullet$ & \\
\hline New Green Revolution & $\bullet$ & $\bullet$ & $\bullet$ & $\bullet$ & $\bullet$ & \\
\hline Organic Wine & $\bullet$ & & & $\bullet$ & & $\bullet$ \\
\hline VinNatur & $\bullet$ & & & & & \\
\hline
\end{tabular}

Notes: The black spot shows the presence of the element in the program (blank cellars mean that the element is not considered by the program). Only for validation, the single dot means that the evaluation has been provided by the program's staff; double dots indicate that the validation has been provided by the program's staff and a third party.

\subsection{Completeness}

As highlighted in the "Introduction", sustainability is often defined as a three-dimensional concept, composed by the environmental, social and economic "pillars" [8]. Although this concept is widely recognized, the fields of application of sustainability are very different: indeed, numerous different sustainable practices are reported in the literature, addressing, for example, soil management, water management, wastewater, biodiversity, solid waste, energy use, air quality, and the use of agrochemicals [5]. This part of the analysis aimed to understand which "pillars" are taken into consideration by each program, as well as which elements within each pillar.

Given that the elements that are useful to assess sustainability in its three dimensions are a wide number, those considered as representative of the pillars were chosen by analyzing the main indicators nowadays used by companies and organizations when assessing and communicating their sustainability performances. Furthermore, a distinction was made between those elements considered "directly" or "indirectly". A certain aspect of sustainability, for example, the impact on water or biodiversity, can be evaluated directly if the winery is asked to assess it through the application of specific indicators, or if a specific questionnaire is designed to extract this information. Alternatively, an element can be considered in an indirect way when the company is not asked to assess it, but the program implicitly considers the aspect. For example, a sustainability program focusing on precision farming, allowing farmers to reduce treatments in the vineyard can, under certain conditions, make them save money and farm in a more effective manner. Here, the economic sustainability is not a direct objective of the program but is without any doubt indirectly considered. 
Table 4. Completeness of programs according to the environmental, economic and social aspects of sustainability included in the program itself* .

\begin{tabular}{|c|c|c|c|c|c|c|c|c|c|c|c|c|c|c|c|c|c|c|}
\hline \multirow[b]{2}{*}{ Programs } & \multicolumn{11}{|c|}{ ENVIRONMENTAL } & \multicolumn{3}{|c|}{ ECONOMIC } & \multicolumn{4}{|c|}{ SOCIAL } \\
\hline & $\mathbf{A}$ & $\mathbf{W}$ & $\mathbf{S}$ & B & $\mathbf{E}$ & $\mathbf{P k}$ & $\mathbf{T}$ & PF & Ws & $\mathbf{L}$ & $\mathbf{R M}$ & Dir & In & Loc & Em & $\mathbf{R}$ & $\mathbf{C m}$ & Cn \\
\hline \multirow{2}{*}{$\begin{array}{l}\text { Tergeo } \\
\text { Matrix * Applications }\end{array}$} & $\bullet$ & $\bullet$ & $\bullet$ & • & & & & $\bullet$ & & $\bullet$ & & & & & & $\bullet$ & • & - \\
\hline & $*$ & $*$ & * & $*$ & * & * & $*$ & $*$ & * & $*$ & $*$ & & $*$ & & $*$ & $*$ & * & $*$ \\
\hline Magis & & $\bullet$ & - & - & & & & $\bullet$ & & & & - & & & $\bullet$ & $\bullet$ & & • \\
\hline SOStain & $\bullet$ & $\bullet$ & $\bullet$ & $\bullet$ & $\bullet$ & $\bullet$ & $\bullet$ & $\bullet$ & $\bullet$ & $\bullet$ & $\bullet$ & $\bullet$ & $\bullet$ & $\bullet$ & $\bullet$ & • & - & $\bullet$ \\
\hline V.I.V.A. & $\bullet$ & $\bullet$ & $\bullet$ & $\bullet$ & $\bullet$ & $\bullet$ & $\bullet$ & - & - & $\bullet$ & $\bullet$ & & - & $\bullet$ & - & • & - & • \\
\hline ECO-Prowine & $\bullet$ & - & $\bullet$ & & $\bullet$ & $\bullet$ & - & $\bullet$ & $\bullet$ & & & • & & & $\bullet$ & - & • & - \\
\hline Ita.Ca/Gea.Vite & $\bullet$ & $\bullet$ & $\bullet$ & $\bullet$ & $\bullet$ & $\bullet$ & $\bullet$ & $\bullet$ & $\bullet$ & $\bullet$ & & $\bullet$ & & & $\bullet$ & $\bullet$ & $\bullet$ & • \\
\hline Vino Libero & & $\bullet$ & $\bullet$ & $\bullet$ & $\bullet$ & $\bullet$ & $\bullet$ & - & - & • & & - & & & - & & & - \\
\hline New Green Revolution & $\bullet$ & $\bullet$ & $\bullet$ & • & $\bullet$ & $\bullet$ & - & - & $\bullet$ & $\bullet$ & $\cdot$ & $\bullet$ & $\bullet$ & & $\bullet$ & $\bullet$ & - & • \\
\hline Organic Wine & & $\cdot$ & $\cdot$ & - & & & & $\bullet$ & & & - & & & & & & & • \\
\hline VinNatur & & $\cdot$ & - & - & & & & - & & & & & & & & & & - \\
\hline
\end{tabular}

* The black point means that the aspect is completely assessed. The grey point indicates that the aspect is not considered in a direct way (e.g., a program promoting less use of chemicals could indirectly lead to an increased economic efficiency, consisting in cost reductions). Legend: A: Air; W: Water (impact on its quality and quantity); S: Soil (erosion, quality etc.); B: Biodiversity; E: Energy management; Pk: Packaging; T: Transport; Pf: Pesticides and fertilizers; Ws: Waste management; L: Landscape; Rm: Raw materials (sustainability along the supply chain); Dir: Direct economic impacts; In: Indirect economic impacts (the company is committed in activities having a positive return at the local level (e.g., eno-tourism, R\&D activities implemented at a local level, etc.); Loc: Local (Employees/Raw Materials preferably from the local territory); Em: Employees (the company is responsible towards its workers (health, safety, training, working conditions, etc.); R: Residents, Inhabitants (the company is responsible towards people living near the farm); Cm: Community (the company is responsible towards the local community); Cn: Consumers (quality, health, transparency, communication etc. 
The results, shown in the Table 4, are clear: the majority of the programs take into account the three dimensions of sustainability, but, in doing this, they use a different level of specification. The most complete programs seem to be Tergeo, V.I.V.A., New Green Revolution 2015 and SOStain (the two last, however, are characterized by a strong "territorial vocation"). The VinNatur Consortium and Organic Wine take into account mainly the environmental aspect. The social pillar is also considered but referring particularly to food safety (they aim to provide consumers with a wine with a very limited content of sulphites and chemical residues).

\subsection{Boundaries}

The boundary analysis aimed at highlighting the extent of the sustainability assessment proposed by each program in terms of "physical" boundaries (vineyard and winery).

As shown in Table 5, almost all programs aimed to assess and improve the sustainability performances both in the field and the vineyard, except for Magis that — at least for the moment - is mainly focused on "precision agriculture" (hence, on the field). Of course, these results for boundaries should be analyzed in comparison with the elements previously considered in the "Completeness" analysis, in order to avoid interpreting all the programs as being at the same completeness level just because operations in both the vineyard and the winery are considered.

Table 5. "Physical boundaries" of analyzed projects.

\begin{tabular}{llll}
\hline Programs & Vineyard & Winery & Notes \\
\hline Tergeo & $\bullet$ & $\begin{array}{l}\text { Winery considered only by "applications" } \\
\text { (not in the matrix) }\end{array}$ \\
\hline Magis & $\bullet$ & $\bullet$ & \\
\hline SOStain & $\bullet$ & $\bullet$ & \\
\hline V.I.V.A. & $\bullet$ & $\bullet$ & \\
\hline ECO-Prowine & $\bullet$ & $\bullet$ & - \\
\hline Ita.Ca/Gea.Vite & $\bullet$ & $\bullet$ & regulation of sulphites, chemicals and \\
\hline Vino Libero & $\bullet$ & $\bullet$ & additives (food safety). \\
\hline New Green & $\bullet$ & & \\
\hline Revolution & $\bullet$ & $\bullet$ & \\
\hline VinNatur & $\bullet$ & $\bullet$ &
\end{tabular}

Notes: The black spot indicates the areas (Vineyard/Winery) considered within each program. The grey spot means that the program provides "sustainability indications" only in relation to certain parts of the area.

\subsection{Consistency (Science and Innovation)}

A criteria, (certainly not exhaustive, but definitely relevant), to examine the scientific nature of a program is the presence of members belonging to Universities, Research Centers, and the scientific community. All such members can participate in the program as promoter subjects or as part of the scientific/technical committee. In the table, the scientific subject within each program has been listed. 
In this analysis, consistency is also given by the "grade" of innovation and originality of programs. Given that each program always start from existing regulations and legislations (especially regarding the aspects related to food safety, hygiene and safety at work), it is possible to state that not all the programs have the same grade of originality for dealing with sustainability. Tables 6 and 7 show the results for both these aspects.

Looking at Table 6, it is possible to notice how different the "innovation proposal" of each program is. Some programs are a "synthesis" of existing protocols, rules or "good practices" already in practice, but usually ensuring the final consumer a higher level of quality for wines produced by companies joining the program. The innovation grade is higher for those programs that propose a detailed sustainability assessment through check-lists, questionnaires, on-line tools, etc. Finally, the innovation is at a maximum level for initiatives introducing completely new methodologies, equipment, indicators, and management tools to assess and enhance sustainability performance.

Table 6. Academic Bodies/Research Centers and Institutions involved in the projects.

\begin{tabular}{|c|c|c|}
\hline Programs & University/Research Center & Institutions \\
\hline Tergeo & $\begin{array}{l}\text { University of Milan; } \\
\text { University Cattolica del Sacro Cuore, Piacenza } \\
\text { University of Verona; } \\
\text { University of Naples "Federico II"; } \\
\text { University of Padova }\end{array}$ & $\begin{array}{l}\text { Regional Delegate; } \\
\text { Ministry for Rural Policies }\end{array}$ \\
\hline Magis & $\begin{array}{l}\text { University of Milan; } \\
\text { University of Turin (Department of Agrarian, Forest and } \\
\text { Food Sciences); } \\
\text { University of Florence (Department of Economics, } \\
\text { Engineering, Agrarian and Forest Sciences and } \\
\text { Technologies); } \\
\text { University of Bari (Institute of Sciences of Food } \\
\text { Production-National Research Council) }\end{array}$ & \\
\hline SOStain & $\begin{array}{l}\text { University Cattolica del Sacro Cuore, Piacenza (OPERA) } \\
\text { University of Milan; } \\
\text { University of Palermo }\end{array}$ & $\begin{array}{l}\text { Ministry of Rural Policies } \\
\text { (sponsorship) }\end{array}$ \\
\hline V.I.V.A. & $\begin{array}{l}\text { University Cattolica del Sacro Cuore (OPERA); } \\
\text { University of Turin (Agroinnova); } \\
\text { University of Perugia (Res.Cent. on Biomasses) }\end{array}$ & $\begin{array}{l}\text { Ministry for the Environment, } \\
\text { Land and Sea }\end{array}$ \\
\hline ECO-Prowine & $\begin{array}{l}\text { University Cattolica del Sacro Cuore, Piacenza (OPERA); } \\
\text { Research Centers: IPVE (Portugal), Aeiforia (University } \\
\text { Cattolica), CIRCE (University of Zaragoza) }\end{array}$ & $\begin{array}{l}\text { European Community (framework } \\
\text { Competitiveness and Innovation } \\
\text { Framework Programme- } \\
\text { EcoInnovation) }\end{array}$ \\
\hline Ita.Ca/Gea.Vite & University of Milan & \\
\hline Vino Libero & University of Turin & $\begin{array}{l}\text { Piedmont Region (Framework: } \\
\text { European Agricultural Fund for } \\
\text { the Rural Development) }\end{array}$ \\
\hline
\end{tabular}


Table 6. Cont.

\begin{tabular}{lll}
\hline Programs & University/Research Center & Institutions \\
\hline & University of Milan; & \\
New Green Revolution & $\begin{array}{l}\text { Parco Tecnologico Agroalimentare Umbria 3A- Agrifood } \\
\text { Technological Park of the Umbria Region); } \\
\text { ConfAgricoltura Umbria }\end{array}$ & $\begin{array}{l}\text { PSR/Innovation; } \\
\text { Umbria Region }\end{array}$ \\
\hline \multirow{2}{*}{ Organic wine } & & European Community \\
& & Regulation No. 203/2012. \\
\hline VinNatur & Experimental Center for Sustainable Viticulture & \\
\hline
\end{tabular}

Table 7. Main innovations generated by each program.

\begin{tabular}{|c|c|}
\hline Programs & Programs' Innovations \\
\hline Tergeo & $\begin{array}{l}\text { It is the first "platform" aiming to collect sustainability tools and initiatives. It is able to link } \\
\text { requests from winemakers and farmers with the solutions and products proposed by companies, } \\
\text { Universities, etc. } \\
\text { Applications: tools innovative by definition, they are all validated according to a scientific } \\
\text { process. } \\
\text { "Tergeo" matrix for the evaluation of sustainability positioning. }\end{array}$ \\
\hline Magis & $\begin{array}{l}\text { Focus on "precision farming" and innovation in the sector. } \\
\text { The Platform enables the continuous monitoring by researchers and improvement for farmers. } \\
\text { Label and validation by a Third Party. }\end{array}$ \\
\hline SOStain & $\begin{array}{l}\text { First complete sustainability program for wineries in Sicily (it assesses environmental, social } \\
\text { and economic sustainability along all the chain). Strong focus on a specific territory. } \\
\text { Transparency towards consumers (companies are obliged to edit a sustainability report). }\end{array}$ \\
\hline V.I.V.A. & $\begin{array}{l}\text { Use of completely new indicators, or existing ones but adapted to the wine sector. } \\
\text { High transparency (disciplinary is public) and involvement of a Third Party for the } \\
\text { disciplinary evaluation. } \\
\text { Communication: innovative way of communicating with the final consumer through a specific } \\
\text { label, QR (Quick Response) Code and smart-phone app. } \\
\text { Procedure to obtain the label: it is necessary to be verified by a third party that can be chosen } \\
\text { by the single winery. }\end{array}$ \\
\hline ECO-Prowine & $\begin{array}{l}\text { Application of LCA-LCC methodology specifically adapted to the wine sector } \\
\text { Creation of a specific "label" for sustainable wine that can be recognized across all Europe as a } \\
\text { standard in the sector. } \\
\text { Statistical approach to obtain the influencing factors in the impact indicators. } \\
\text { Program including European different countries. }\end{array}$ \\
\hline Ita.Ca/Gea.Vite & $\begin{array}{l}\text { Ita.Ca: first GHG emissions calculator for the Italian wine sector. } \\
\text { Integration of social and economic sustainability with elements related to an effective } \\
\text { management of the winery. }\end{array}$ \\
\hline Vino Libero & $\begin{array}{l}\text { The Disciplinary aims to combine, in a harmonic manner and as an "improved summary", the } \\
\text { requirements from national and regional guidelines for organic and integrated production. } \\
\text { Ability of the program to involve - a part from wineries - also wine houses, restaurants, etc. }\end{array}$ \\
\hline
\end{tabular}


Table 7. Cont.

\begin{tabular}{ll}
\hline Programs & Programs' Innovations \\
\hline \multirow{3}{*}{ New Green Revolution } & $\begin{array}{l}\text { Strong focus on local territory (Montefalco area, in Umbria Region). } \\
\text { Application and adjustment of GeaVite's tools to a specific area. } \\
\text { Realization of a new machine that can enhance sustainability in farming. } \\
\text { Involvement of a Third Party for the validation of the protocol and of companies }\end{array}$ \\
\hline \multirow{2}{*}{ Organic wine } & $\begin{array}{l}\text { Innovative when it was at first proposed (proposing an "alternative" way of farming), } \\
\text { nowadays is only the "protocol” that can give rise to a certification. }\end{array}$ \\
\hline \multirow{2}{*}{ VinNatur } & $\begin{array}{l}\text { It is the first consortium aiming to join all the producers of natural wine across Europe } \\
\text { and promote research in this sector. }\end{array}$ \\
\hline
\end{tabular}

\subsection{Transparency and Communication}

Elements considered in this part of the analysis were the following:

- Reporting: does the program ask wineries to edit and publish a report about sustainability performance and improvement?

- Availability of the evaluation system: is the "evaluation system" available to the final consumers? Are consumers allowed to know how the program assesses a company's sustainability?

- Web: does the program communicate to consumers via a dedicated web-site? Is information clear and transparent?

- Label: is a "sustainability label" provided as the final output of the program, in order to allow the final consumer to recognize products and companies committed in a sustainability-improving path?

Results are shown in Table 8.

Table 8. Results for the analysis regarding the transparency and accessibility of information given to final consumers.

\begin{tabular}{ccccc}
\hline Programs & Report & Evaluation System & Web & Label \\
\hline Tergeo & & & $\bullet$ & \\
\hline Magis & & & $\bullet$ & $\bullet$ \\
\hline SOStain & $\bullet$ & & $\bullet$ & \\
\hline V.I.V.A. & $\bullet$ & $\bullet$ & $\bullet$ \\
\hline ECO-Prowine & $\bullet$ & $\bullet$ & $\bullet$ \\
\hline Ita.Ca/Gea.Vite & $\bullet$ & $\bullet$ & \\
\hline Vino Libero & $\bullet$ & $\bullet$ & $\bullet$ \\
\hline New Green Revolution & & $\bullet$ & $\bullet$ \\
\hline Organic Wine & $\bullet$ & $\bullet$ & $\bullet$ \\
\hline VinNatur & & $\bullet$ & $\bullet$ &
\end{tabular}

Notes: The black spot indicates the presence of the communication and informational tools within each program: the report, (the availability of) the evaluation system, the specific web site and the label); The grey spot means that the element is only partially used in the program. 
Regarding the "Report", only SOStain specifically asks its wineries to edit a sustainability report, presenting the main results of the implemented program.

The issue of the "Evaluation System" is quite controversial, due to the fact that the majority of programs allow the final consumers to know how the sustainability assessment is conducted (i.e., which parameters were evaluated), but not all programs offer the same level of transparency (in terms of provided information). In this sense, the highest values of transparency seemed to be reached by V.I.V.A. (its manuals are publicly available) and ECO-Prowine (the assessment manual for wineries is available on the website of the project). The Vino Libero disciplinary is available on the website of the project, as well as the one for VinNatur: the consumer can know the "topics" considered by the programs but no detailed information is provided. Particularly for Vino Libero, the disciplinary is available on the website, nevertheless is not really clear how a company's compliance with it is assessed (except for the content of sulphites).

The regulation for Organic Wine is available on the website of the European Community. Finally, regarding Gea.Vite Evaluation System is not public; the Ita.Ca's protocol is made upon the OIV-GHG (Organisation Internationale de la Vigne et du Vin-Greenhouse Gas) emission calculator that is publicly available (on the OIV website)

"Web Site": as shown in the table, all the programs have a specific website, a part from the Ita.Ca and Gea.Vite programs, for which information is contained in a specific part of the Agronomi Sata's website. Regarding Organic Wine, it is possible to find information regarding Organic Farming on the website of the European Community [45]; more information regarding the specific product "wine", in Italy, is available on the website of Federbio [46].

"Label": communication to consumers using a sustainability label is not provided by all the programs. V.I.V.A. and Magis are going to release their sustainability label, which will enable consumers to recognize wines produced according to their specific protocols or rules. The ECO-Prowine projects will release a sustainability label by the end of 2014, as stated in the objectives of the program. "New Green Revolution" has created a collective brand. Its use is not mandatory for wineries; indeed, after the validation, they can ask to use the logo on bottles, advertising materials etc. (but they have to specify that the logo refers to the sustainability of the processes and not to the specific product). Finally, Vino Libero also provided a label that is applied to the neck of the bottles produced in compliance with its disciplinary.

\subsection{Validation and Third Party Intervention}

Given the difference between validation and certification explained in Chapter 3, the analysis on sustainability programs has highlighted that, in general, all the programs considered expect a "check" on the performances of their members, to ensure they adhere to the program's guidelines and objectives. Nevertheless, there is a certain difference in the way these checks are provided. In some cases, only a check about the methodology's application is provided; other times, some threshold values are set, and the sustainability assessment outcomes have to be maintained within a certain limit (usually this is the case for programs having, as an output, a label or a certificate, that cannot be gained if the company is outside the set values/required improvement has not been achieved). 
Regarding the "Validation and third party intervention" parameters, the analysis has been conducted distinguishing between the following:

- In/Out: the validation/certification is guarantees adherence to the rules stated in the protocol/disciplinary. Maintaining the membership status is not a matter of thresholds, but rather related to do/not to do requirements.

- Gradual (scale): the check is made upon thresholds, and the achievement of levels of sustainability.

During this phase, the involvement of a third party for the validation or certification has been also considered.

Results are shown in Table 9.

It is clear from the table that-given that a program can release a "certification" only when the guidelines have been established by a regulatory international Organisation (e.g., by the International Standard Organization) - only the Organic Wine can award a certification. For other programs, it is always better to use the word "validation".

Table 9. Results for the analysis regarding the validation, certification and third party involvement in the program.

\begin{tabular}{|c|c|c|c|c|}
\hline \multirow{2}{*}{ Validation/Certification } & \multicolumn{2}{|c|}{ Check on Values } & \multicolumn{2}{|c|}{ Involvement of a 3rd Party } \\
\hline & In/Out & Gradual (scale) & Validation & Certification \\
\hline Tergeo $^{1}$ & & $\bullet$ & $\bullet$ & \\
\hline Magis $^{2}$ & & $\bullet$ & $\bullet$ & \\
\hline SOStain & & $\bullet$ & & \\
\hline V.I.V.A. & & $\bullet$ & $\bullet$ & \\
\hline ECO-Prowine $^{3}$ & & $\bullet$ & & \\
\hline Ita.Ca+Gea.Vite ${ }^{4}$ & & $\bullet$ & & $\cdot$ \\
\hline Vino Libero & $\bullet$ & & & \\
\hline New Green Revolution ${ }^{5}$ & & $\bullet$ & $\bullet$ & \\
\hline Organic Wine & $\bullet$ & & & $\bullet$ \\
\hline VinNatur & $\bullet$ & & & \\
\hline
\end{tabular}

Notes: The black spot indicates the type of verification or certification (if provided) of each program; the grey spot means the partial presence of the element. ${ }^{1}$ Tergeo: Validation on gradual values foreseen in the future, with the respect of a minimum threshold. Involvement of a 3rd party for validation foreseen in the future; ${ }^{2}$ Magis: validation on gradual scale foreseen in the future to gain a different colored label; ${ }^{3}$ ECO-Prowine: Sustainability label foreseen; ${ }^{4}$ Ita.Ca/Gea.Vite: Certification can be provided but only for the Carbon Footprint (for which an ISO Standard exists); ${ }^{5}$ New Green Revolution: a validation on gradual scale is required to gain the logo.

Companies joining the Ita.Ca program can ask for the ISO14064 certification, since the Carbon Calculator proposed by Ita.Ca is in compliance with the ISO rule.

Programs such as V.I.V.A. or New Green Revolution involve a third party verifier at a double level: for the validation of the protocol/disciplinary and for checks on companies joining the program.

Other programs - at least at the present moment—verify the compliance of the company with the program's requirements and/or the achievement of threshold values. 


\section{Discussion}

The results of this study indicate that, in general, no one sustainability program is "better" than the other, because any comparison always has to take into account the specific objective that each program aims to gain and the peculiarities of the companies they address (size, wine quality, etc.). However, considering the final objective of the study, which is to understand if it is possible to draw a common line between the sustainability initiatives, the analysis highlighted some important similarities and differences among the programs. Table 10 summarizes the main elements evaluated in the analysis.

Table 10. Final results of the analysis *.

\begin{tabular}{|c|c|c|c|c|c|c|c|c|c|c|c|c|c|c|c|c|c|c|c|}
\hline \multirow[t]{2}{*}{ Programs } & \multicolumn{5}{|c|}{ Elements } & \multicolumn{3}{|c|}{ Pillars } & \multicolumn{2}{|c|}{ Objective } & \multicolumn{2}{|c|}{ Boundaries } & \multicolumn{3}{|c|}{$\begin{array}{l}\text { Transparency \& } \\
\text { Communication }\end{array}$} & \multicolumn{2}{|c|}{ Validation } & \multicolumn{2}{|c|}{$\begin{array}{l}\text { 3rd Party } \\
\text { Intervention }\end{array}$} \\
\hline & $\begin{array}{l}\overline{7} \\
\overline{0} \\
\overline{0} \\
\stackrel{0}{-}\end{array}$ & 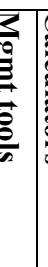 & 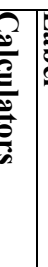 & $\bar{E}$ & 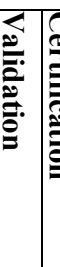 & 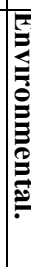 & 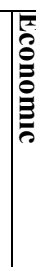 & & 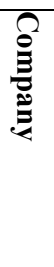 & 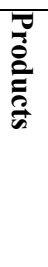 & 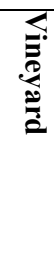 & $\stackrel{\varrho}{=}$ & $\frac{\pi}{0}$ & 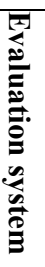 & $\begin{array}{l}\sum_{0} \\
0 \\
0 \\
\stackrel{0}{0}\end{array}$ & $\begin{array}{l}\bar{E} \\
\Xi\end{array}$ & 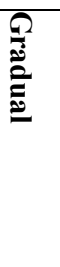 & 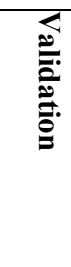 & 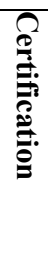 \\
\hline Tergeo & & $\bullet$ & & & • & & & & $\bullet$ & & $\bullet$ & $\bullet$ & & & $\bullet$ & & $\bullet$ & & \\
\hline Magis & $\bullet$ & $\bullet$ & & - & $\bullet$ & & . & & & - & - & & & & - & & - & - & \\
\hline SOStain & $\bullet$ & $\bullet$ & • & & • & & 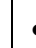 & & - & & - & - & - & & - & & - & & \\
\hline V.I.V.A. & & $\bullet$ & $\bullet$ & $\bullet$ & $\bullet$ & & . & & - & - & - & - & & - & - & & - & - & \\
\hline Vino Libero & $\bullet$ & $\bullet$ & & $\bullet$ & $\bullet$ & & ? & & & $\bullet$ & - & $\bullet$ & & $\bullet$ & $\bullet$ & $\bullet$ & & & \\
\hline $\begin{array}{l}\text { New Green } \\
\text { Revolution }\end{array}$ & & $\bullet$ & $\bullet$ & - & $\bullet$ & & s & & - & & - & - & & & $\bullet$ & & • & - & \\
\hline Ita.Ca/GeaVite & $\bullet$ & $\bullet$ & $\bullet$ & & $\bullet$ & & . & & $\bullet$ & & $\bullet$ & $\bullet$ & & $\bullet$ & - & & $\bullet$ & & - \\
\hline ECO-Prowine & & $\bullet$ & $\bullet$ & $\bullet$ & $\bullet$ & & ra & & $\bullet$ & & $\bullet$ & $\bullet$ & & $\bullet$ & $\bullet$ & & $\bullet$ & & \\
\hline Organic wine & $\bullet$ & & & - & & & & & & $\bullet$ & • & $\bullet$ & & $\bullet$ & - & • & & & - \\
\hline VinNatur & & & & & & & & & & - & - & - & & - & - & - & & & \\
\hline
\end{tabular}

Notes: The black spot indicates that the aspect is completely taken into consideration; the grey spot that the element is partially considered.

\subsection{Common Aspects}

Integration of the social and economic pillars: compared with the past, when - talking about sustainability - the attention of farmers, producers, and stakeholders in general was mainly on the environmental or social impact. Nowadays (as shown by the analyses) the initiatives tend to aim to assess the companies' sustainability in a more complete and integrated way, considering all the three pillars. Not only environmental, but also social and economic sustainability are hence considered fundamental in order to say that a winery is sustainable. 
Completeness in the boundaries definition. Almost all the analyzed programs provide a sustainability assessment both in the vineyard and the winery, even if the level of detail is very different among initiatives: for example, the Organic Wine protocol regulates mainly food safety aspects, whereas programs such as SOStain or V.I.V.A. aim to assess sustainability along all the chain, including aspects related to the winery and the wine production (e.g., water consumptions, waste management, etc.).

Management tools: questionnaires. The use of questionnaires and check-lists proposed to companies seems to be quite common, in order to collect data and/or understand and calculate the level, or the positioning of a winery in the path towards sustainability. Although in a different way and with a different level of detail, this management tool is used by Tergeo (matrix), Magis, V.I.V.A, SOStain, ECO-Prowine, Gea.Vite, and New Green Revolution.

Existing good practices and standards as a base. It is possible to state that the majority of sustainability initiatives are consistent from a scientific point of view since they are "inspired" by agricultural good practices, laws and standards in the wine sector etc. This is a good starting point: in any case, the "added value" of each program was analyzed according to its "originality" and innovation. In addition, the majority of initiatives are carried on in cooperation with Universities, Research Centers, etc. (although in a different grade).

\subsection{Differences}

The main differences between programs can be found in:

Level of detail applied to analyze the different aspects of sustainability. Given that, as previously said, the three pillars of sustainability are considered by nearly all the programs, it is possible to detect big differences in the elements and indicators used by each program to assess sustainability within its pillars. Especially with regard to social and economic aspects, initiatives are characterized by many differences. Hence, programs such as SOStain (with its specific check-list for the evaluation of social and economic sustainability) and V.I.V.A. (specific indicators for social and economic sustainability have been created as a relevant part of the project) are strongly focused on all the pillars; other programs investigate these aspects in a superficial way, for example dedicating them just a few questions within an entire check-list. It is fundamental to take these differences into consideration, by virtue of the strong social impact of viticulture being based on the physical work and being strongly linked to the territory (landscape, tourism, etc.).

Grade of innovation. Being innovative, proposing something truly new in order to enhance sustainability in the sector: this should be the main parameter to be considered when analysing and comparing sustainability initiatives. As previously underlined, building a program on the base of existing laws and regulations is important (e.g., promoting safe conditions in the work place, fair salaries, avoid gender discrimination, complying with the minimum environmental requirement, and with the product safety laws): nevertheless, it is necessary that a program is able to go beyond, to be characterized by a minimum grade of innovation that is necessary proposing a mere "reorganization" of something that already exists and is defined by rules or standardized. This would only confuse consumers; why they should commit to a sustainability program, investing effort, money and time, to do something that is already mandatory by law. 
In this sense, indicators, methodologies not previously used, and new technologies and products are examples of what we mean by "innovation".

V.I.V.A. is characterized by innovation in the use of new indicators-specifically created for the project (Vineyard and Territory) - and new communication tools (Quick Response (QR) Code and smart phone app). SOStain and New Green Revolution are characterized by the strong "territorial vocation" (Sicily and Umbria, respectively).

Ita.Ca was the first carbon calculator for the Italian wine sector, and Gea.Vite is characterized by the final objective: to extend the analysis at the organization's efficiency and the use of weighing factors in the sustainability's level assessment.

Tergeo is particularly innovative for its "double" nature: the Matrix of sustainability, just finished being defined by Tergeo's researchers, is an innovative tool that enables companies to assess their "positioning" in the sustainability path (but only for the vineyard area for the moment). Tergeo's "Applications" are innovative "by nature": indeed, they are approved by a Scientific Committee also on the base of their level of innovation. This platform, that aims to match researchers, producers' needs and innovative products and methodologies is, at the moment, unique in the Italian framework.

Transparency and communication. In this context, communication is not always considered a priority, being the focus of the initiatives posed on the improvement of sustainability in the product and/or organization. It is worth noting that communication is becoming increasingly important. Improving sustainability performance and being scientifically consistent are at the base of each program; but, at the same time, it is absolutely necessary to implement effective communication strategies. Considering the increasing interest of consumers towards green products and responsible consumption [47], it is necessary to allow consumers to know about the commitment of companies to sustainability improvement and to make them recognize the more sustainable products.

In the context of this analysis, transparency and communication have been evaluated considering the disclosure of the sustainability results (by means of a report), the possibility for the consumer to be informed about the analysis system (how the sustainability level of a company is evaluated by the program) and the presence of a label.

Regarding the provision of a report - that means that the program asks to its member to produce and publicly release a report about performances gained in the framework of the initiative - only SOStain satisfies this requirement. For example, Tasca D'Almerita, a big Sicilian winery participating in the program, has published a report on its web site presenting the results gained under the framework of the SOStain project [48].

The availability of the evaluation system is an important element to judge the transparency of a sustainability initiative. Usually, the simple fact of being part of a sustainability initiative - particularly when it is promoted by a well-known Organization, Research Center, or Institution - is a guarantee for consumers: but it is the program itself (its scientific-technical staff) that need to guarantee better sustainability performance to consumers. However, does the consumer know how the specific company was evaluated? Are the parameters considered in the analysis known? Unfortunately, it seems that the majority of initiatives do not disclose their evaluation system to the broad public. Sometimes, a Protocol or a Disciplinary is publicly available on the initiative's websites, but — aside from the general rules to be followed to be part of the program and behavior/substances admitted and forbidden in the vineyard and in the cellar - it is not possible to know how audits have been conducted 
and which evaluation parameters have been used. According to these statements, the only programs disclosing the evaluation system are V.I.V.A. (since its disciplinary - that is validated by a third party, in order to ensure they are built in a correct way - is available on the website) and ECO-Prowine (the "Manual" to use the online tool is publicly available on the project website; hence, consumers can read about all the elements considered in the analysis).

A label of sustainability, when it is the output of consistent scientific analysis (and it is not mere green washing), enables consumers to recognize the more sustainable companies and to reward them for the effort by purchasing their product. Although it is not possible to state that a sustainability label can totally influence the choice of a certain products, due to the strong influence of other parameters (particularly in the purchase of food products), and the difficulty to separate the effect of other factors from the effect of the label $[49,50]$, it can be very useful to increase awareness regarding the topic of sustainability and sustainable consumption, and it can increase the influence of sustainability as a choice factor, as declared by consumers [51]. When the label is the expression of a membership to an initiative, or a well-defined sustainability program, and it is supported by an "entity" (e.g., a University, a Research Center, a Public Institution) in which consumers trust, the efficacy of the label can be increased.

From this perspective, the more relevant initiatives are:

- V.I.V.A: a complex label composed by a QR (Quick Response) code (a square code linked to the information about the program and the related product), the four indicators (pictures, not values), the logo and name of the initiative, the logo of the Italian Ministry of the Environment.

- Magis: the label at the moment is a simple logo representing the membership of the company to the program and the achievement of minimum requirement. In the future, the logo will be differently colored according to the sustainability level gained.

- ECO-Prowine: the label, foreseen within 2014, will be the sign that the company is committed to the sustainability program and a minimum set threshold has been gained, as well as an improvement. It will be composed of the logo of the project and a code to be inserted on the dedicated website to gain access to information about sustainability performance of the company.

- Vino Libero: the label, presenting the logo of the project, is the "proof" that a product has been made according to the "Vino Libero" rules.

\section{Conclusions}

Sustainability has become a key issue for the Italian wine industry. Starting from the establishment of a methodology for the comparison of sustainability initiatives in the Italian wine sector, this analysis has highlighted the differences and similarities between them. Indeed, a variety of systems, methodologies and tools are being implemented, for a variety of reasons with different objectives. For example, for the Organic certification, the focus is mainly on reducing environmental impact, whereas in V.I.V.A. sustainability is evaluated in its three dimensions (environmental, economic, and social). When evaluated against their own objectives, all the programs and systems can be judged as effective, but the results can be different if an analysis against the Three Bottom Line (TBL) principles is conducted, and if their completeness (referring to the identified elements presented in the "Glossary") is evaluated too. 
The great spread of sustainability initiatives in the wine sector can be a great opportunity for the overall sector; but confusion and overlapping of initiatives, methodologies and results must be avoided. The key point is that a common notion of sustainability in the Italian wine sector should be promoted, together with a broader industry wide sustainability strategy, and in order to do this it is necessary to foster the cooperation of all the program representatives and researchers. Creating a common understanding of sustainability is crucial for producers as well as for the entire sector. This common understanding is necessary first of all for an effective and beneficial consumer communication $[5,12]$ and to reduce the uncertainty linked to the presence of a wide range of certifications and sustainability labels on the market. Secondly, a common language and framework is needed, one that can be used by the largest possible number of producers and farmers in the sustainability path. The great number of sustainability initiatives and programs can be very confusing for companies, inducing the risk that the real characteristics of each program and the real benefits for the company and the business are not clearly understood by the company's management and ownership. Finally, a single, unique sustainability framework and brand could enhance the competitiveness of Italian wine on foreign markets, particularly on those promoting sustainable products. Sustainability could become a new "distinctive trait" of the Italian wine, the "flagship product" for a "made in Italy and sustainable" production.

Will it be possible to "merge" the different elements of the programs in order to create a single, uniform framework to spread sustainability in the Italian wine sector, at the same time promoting scientific consistency, clarity and transparency towards wineries and consumers? This is the question to be posed to the program promoters. A positive answer seems to be possible, as was also evident Intervention during the stakeholder consultation held during the International Conference SIMEI-Enovitis [52].

As was shown in similar studies [21], results of this kind of analysis show that each of these programs has its own strenghts, but it is not possible to say that one program is better than another: elements considered in one program are sometimes not analyzed in another that, may instead focus on other aspects. On the contrary, there is a general consensus on some aspects, such as the use of certain calculators or methodology to assess sustainability (for example, the calculation of the Carbon Footprint to assess the impact on the air quality or the use of check lists as a tool to evaluate the company's performances).

Starting from these assumptions and the results of the analysis, the authors believe that a unique framework could be created, but it wil be necessary to clearly define:

- The presence and the meaning of the characterizing elements of a real and complete sustainability program (protocol, indicators, the label, etc.) that could be suitable for the Italian wine sector;

- The main areas (e.g., Air, Water, Soil, etc.) to be considered;

- Within each area, shared "indicators" to be used to calculate and compare sustainability performances.

An integration between the programs and their elements, hence, is possible; however, it is necessary that, starting from inputs given by this study, further analysis and initiatives are promoted by stakeholders at an operating level, with the objective of understanding if synergies between programs are possible in practice. The work is surely not easy, due to the complexity of the sustainability 
concept in itself, that is extremely wide and somehow ambiguous. However, by creating an ongoing dialogue and exchange of experiences and opinions between the researchers and promoters that are working for sustainability further analyses will bring concrete results.

\section{Acknowledgments}

The present work has been conducted in the framework of the Italian project V.I.V.A. Sustainable Wine, supported by the Italian Ministry for the Environment, Land and Sea.

The authors would also like to thank the program managers for their availability in providing all the necessary information in order to make this evaluation possible.

\section{Author Contributions}

Chiara Corbo has realized this work in the framework of her research project. Lucrezia Lamastra, as the scientific expert, has supervised the overall work. Ettore Capri, director of the research centre OPERA, has coordinated the initiative.

\section{Conflicts of Interest}

The authors declare no conflict of interest.

\section{References and Notes}

1. Gabzdylova, B.; Raffensperger, J.; Castka P. Sustainability in the New Zealand wine industry: Drivers, stakeholders and practices. J. Clean. Prod. 2009, 17, 992-998.

2. Barber N.; Taylor C.; Strick S. Wine consumers environmental knowledge and attitudes: Influence on willingness to purchase. Int. J. Wine Res. 2009, 1, 59-72.

3. Ohmart, C. Innovative outreach increases adoption of sustainable winegrowing practices in Lodi region. Calif. Agric. 2008, 62, 142-147.

4. Sinha P.; Akoorie, M. Sustainable Environmental Practices in the New Zealand Wine Industry: An Analysis of Perceived Institutional Pressures and the Role of Exports. J. Asia-Pac. Bus. 2010, $11,50-74$.

5. Szolnoki G. A cross-cultural comparison of sustainability in the wine-industry. J. Clean. Prod. 2013, 53, 243-251.

6. Marshall R.; Cordano M.; Silverman M. Exploring Individual and Institutional Drivers of Proactive Environmentalism in the US Wine Industry. Bus. Strat. Environ. 2005, 14, 92-109.

7. Hoffman, M. Keeping the wineglass full: Exploring the intersection of sustainable viticulture and sustaining winegrower legacy in Lodi. Master Thesis, Iowa State University, Ames, IA, USA, 2009.

8. United Nations (UN). Resolution adopted by the General Assembly. 60/1. 2005 World Summit Outcome. Available online: http://unpan1.un.org/intradoc/groups/public/documents/un/ unpan021752.pdf (accessed on 11 November 2013).

9. Castellucci, F. Resolution CST 1/2004, Development of sustainable vitiviniculture. Available online: http://www.oiv.int/oiv/files/3\%20-\%20Resolutions/EN/2004/CST\%2001-2004.pdf (accessed on 10 October 2013). 
10. Castellucci, F. Resolution CST 1/2008, OIV Guidelines for Sustainable Vitiviniculture: Production, Processing and Packaging of Products. Available online: http://www.oiv.int/oiv/ files/3\%20-\%20Resolutions/EN/2008/CST\%2001-2008.pdf (accessed on 10 October 2013).

11. Broome, J.; Warner, K. Agro-environmental partnership facilitate sustainable wine-grape production and assessment. Calif. Agric. 2008, 62, 133-141.

12. Klohr, B.; Fleuchaus, R.; Theuvsen, L. Sustainability: Implementation programs and communication in the leading wine producing countries. Available online: http://www.newgreenrevolution.eu/ documents/Sustainability\%20Programs\%20and\%20communication_Bastian\%20Klohr\%201.pdf (accessed on 20 February 2014).

13. Istituto Nazionale di Economia Agraria (INEA). Sostenibilità ambientale, sociale ed economica della filiera vitivinicola. Available online: http://dspace.inea.it/handle/inea/679 (accessed on 11 November 2013) (In Italian).

14. Santini, C.; Cavicchi, A.; Casini, L. Sustainability in the wine industry: Key questions and research trends. Agric. Food Econ. 2013, 1, 1-14.

15. Bastianoni, S.; Marchettini, N.; Panzieri, M.; Tiezzi, E. Sustainability assessment of a farm in the Chianti area (Italy). J. Clean. Prod. 2001, 9, 365-373.

16. Pulselli, F.; Ciampalini, F.; Leipert, C.; Tiezzi, E. Integrating methods for the environmental sustainability: The SPIn-Eco Project in the Province of Siena. J. Environ. Manag. 2008, 86, 332-341.

17. Marchettini, N.; Panzieri, M.; Niccolucci, V.; Bastianoni, S.; Borsa, S. Sustainability indicators for environmental performance and sustainability assessment of the production of four Italian wines. Int. J. Sust. Dev. World 2003, 10, 275-282.

18. Ardente, F.; Beccali, G.; Cellura, M.; Marvuglia, A. POEMS: A Case Study of an Italian Wine-Producing Firm. Environ. Manag. 2006, 38, 350-364.

19. Bosco, S.; di Bene, C.; Galli, M.; Remorini, D.; Massa, R.; Bonari, E. Greenhouse gas emissions in the agricultural phase of wine production in the Maremma rural district in Tuscany, Italy. Ital. J. Agron. 2011, 6, 93-100.

20. Vazquez-Rowe, I.; Rugani, B.; Benetto, E. Tapping carbon footprint variations in the European wine sector. J. Clean. Prod. 2013, 43, 146-155.

21. Hughey, K.; Tait, S.; O'Connell, M. Qualitative evaluation of three "environmental management systems" in the New Zealand wine industry. J. Clean. Prod. 2005, 13, 1175-1187.

22. Warner, K. The quality of sustainability: Agroecological partnerships and the geographic branding of California winegrapes. J. Rural Stud. 2007, 23, 142-155.

23. Forbes, S.; Cohen, D.; Cullen, R.; Wratten, S.; Fountain, D. Consumer attitudes regarding environmentally sustainable wine: An exploratory study of the New Zealand marketplace. J. Clean. Prod. 2009, 17, 1195-1199.

24. Jang, Y.J.; Bonn, M.A. Consumer Purchase Intentions of Organic Wines. Available online: $\mathrm{http}: / /$ scholarworks.umass.edu/cgi/viewcontent.cgi?article=1272\&context=gradconf_hospitality (accessed on 20 February 2014).

25. Fotopoulos, C.; Krystallis, A.; Ness, M. Wine produced by organic grapes in Greece: Using means-end chains analysis to reveal organic buyers' purchasing motives in comparison to non-buyers. Food Qual. Prefer. 2003, 14, 549-566. 
26. Remaud, H.; Mueller, S.; Chvyl, P.; Lockshin, L. Do Australian Wine Consumers Value Organic Wine? Available online: http://academyofwinebusiness.com/wp-content/uploads/2010/04/ Do-Australian-wine-consumers-value-organic-wine_paper.pdf (accessed on 12 February 2014).

27. Sirieix, L.; Remaud, H. Consumer perceptions of eco-friendly vs. conventional wines in Australia. Available online: http://academyofwinebusiness.com/wp-content/uploads/2010/04/SirieixRemaudConsumer-perceptions-of-eco-friendly-wines.pdf (accessed on 20 February 2014).

28. Mueller, R.; Remaud, H. Are Australian wine consumers becoming more environmentally conscious? Robustness of latent preference segments over time. Available online: http://academyofwinebusiness.com/wp-content/uploads/2010/04/MuellerRemaud-Are-Australianwine-consumers-environmentally-conscious.pdf (accessed on 20 February 2014).

29. Schleenbecker, R.; Hamm, U. Consumers' perception of organic product characteristics. A review. Appetite 2013, 71, 420-429.

30. Associazione Italiana per l'Agricoltura Biologica (AIAB). Available online: http://www.aiab.it/ index.php?option $=$ com_content\&view $=$ category\&layout $=$ blog\&id=28\&Itemid $=61 \quad$ (accessed on 12 February 2014).

31. Specific files created for each program are available from the authors upon request.

32. It was not possible to find a clear definition of "Sustainability Protocol" in the literature. In this context, the meaning of the word "Protocol" has been taken from the Information \& Communication Technology, communication and medical sectors. In these areas, indeed, this word is frequently used, although with different meanings. Although the different situations, generally speaking it is possible to notice that all the "protocols" have some common elements: (a) the existence of a precise goal (e.g., the communication between devices in the ICT, the understanding between individuals or entities in the communication field, the resolution of an emergency situation in the medical sector); (b) a set of rules to apply, code of procedures or parameters to own, in order to achieve that goal.

33. The meaning of all these aspects was carefully explained to the interviewed persons. All these elements were chosen according to the "areas" generally considered in the major international sustainability programs, particularly the California Code of Sustainable Winegrowing of the California Sustainable Winegrowing Alliance.

34. Unione Italiana Vini. Tergeo. Available online: http://www.uiv.it/progettotergeo/ (accessed on 11 November 2013).

35. Magis. Che cosa è Magis? Available online: http://magisvino.imagelinenetwork.com/default.cfm (accessed on 11 November 2013). (In Italian)

36. SOStain. II progetto. Available online: http://www.sostain.it/IT/SOStain.aspx (accessed on 11 November 2013).

37. Sustainability in the Italian viticulture. Available online: http://www.viticolturasostenibile.org/ EN/Home.aspx (accessed on 11 November 2013).

38. ECO-Prowine. ECO-Prowine-Approach. Available online: http://www.ecoprowine.eu/approach/ (accessed on 11 November 2013).

39. Ita.Ca. Italian Wine Carbon Calculator. Available online: http://www.agronomisata.it/ template.php?pag=18069 (accessed on 11 November 2013). 
40. Gestione dell'Efficienza Aziendale. Available online: http://www.agronomisata.it/template.php? pag=18072 (accessed on 11 November 2013). (In Italian)

41. Associazione Vino Libero. Disciplinare tecnico di produzione vitivinicola integrata evoluta. Available online: http://www.vinolibero.it/wp-content/uploads/2013/04/Disciplinare-Tecnico-VinoLibero.pdf (accessed on 13 November 2013) (In Italian)

42. New Green Revolution. Elaborazione, introduzione e applicazione di un nuovo protocollo di produzione. Available online: http://www.newgreenrevolution.eu/ (accessed on 11 November 2013). (In Italian)

43. European Commission. Commission Implementing Regulation (EU) No. 203/2012 amending Regulation (EC) No 889/2008 laying down detailed rules for the implementation of Council Regulation (EC) No 834/2007, as regards detailed rules on organic wine.

44. Associazione Viticoltori Naturali. Vinnatur. Available online: http://www.vinnatur.org/ (accessed on 11 November 2013). (In Italian)

45. European Commission. Agricultural and Rural Development. Organic Farming. Available online: http://ec.europa.eu/agriculture/organic/ (accessed on 12 February 2014).

46. FederBio. Il Vino Biologico. Available online: http://www.federbio.it/Vino_biologico.php. (accessed on 12 February 2014). (In Italian)

47. European Commission. Attitudes of European towards building the single market for green products. Available online: http://ec.europa.eu/public_opinion/flash/fl_367_en.pdf (accessed on 11 November 2013).

48. OPERA Research Center. SOStain Sustainable Development Report-Tasca d'Almerita 2012. Available online: http://tascadalmerita.it/pdf/report_2012.pdf (accessed on 10 November 2013).

49. Gallaraga Gallastegui, I. The use of eco-labels: A review of the literature. Eur. Environ. 2002, 12, 316-331

50. Vanclay, J.; Shortiss, J.; Aulsebrook, S.; Gillespie, A.; Howell, B.; Johanni, R.; Maher, M. Customer Response to Carbon Labelling of Groceries. J. Consum. Policy 2011, 34, 153-160.

51. ECO-PROWINE. Life Cycle perspective for Low Impact Winemaking and Application in EU of Eco-innovative Technologies. Available online: http://www.ecoprowine.eu/media/uploads/d4.5 market_analysis_report.pdf (accessed on 10 November 2013).

52. Corbo, C. Dialogo e armonizzazione. Parole chiave per lo sviluppo sostenibile in viticoltura. Available online: http://www.uiv.it/wp-content/uploads/2013/12/p_03_05_simei-convegni.pdf (accessed on 12 February 2014) (In Italian).

(C) 2014 by the authors; licensee MDPI, Basel, Switzerland. This article is an open access article distributed under the terms and conditions of the Creative Commons Attribution license (http://creativecommons.org/licensesby/3.0/). 